\title{
O JOGO DE ESCONDE-ESCONDE Trabalho perigoso e ação social defensiva entre motoboys de Salvador*
}

\author{
Eduardo Paes-Machado \\ Maria Angélica Riccio-Oliveira
}

\section{Introdução}

Os trabalhadores de moto-entrega ou motoboys são um traço saliente da cena urbana brasileira contemporânea. Mais recentes, numerosos e indiscretos que seus equivalentes norte-americanos e europeus, os motoboys transportam em suas motocicletas uma vasta gama de encomendas: desde remédios, alimentos e flores, passando por garra-

* Agradecemos a Capes pela oportunidade de um estágio de pós-doutorado no Centre for Criminological Research, School of Law, University of Sheffield, Reino Unido, no segundo semestre de 2007, onde este trabalho começou a ser elaborado. Agradecemos também a Joanna Shapland, Simon Holdaway, Philip Stenning, Christopher Birkbeck, Tony Jefferson, Stevie Edgell, Phil Hardfield, Teela Sanders, Sérgio Adorno e aos comentaristas anônimos deste artigo.

Artigo recebido em abril/ 2008

Aprovado em abril/2009 fas de água mineral, até celulares, cartões de crédito e dinheiro. ${ }^{1}$ A expansão dos serviços de moto-entrega - por causa de congestionamento das vias urbanas, praticidade para o consumidor, baixos custos da mão-de-obra, ${ }^{2}$ facilidade de ingresso na ocupação, autonomia e excitação proporcionadas pela condução de veículos versáteis - converteu este trabalho em um pólo de atração para adultos e jovens do sexo masculino.

Trata-se de uma atração fatal ou quase fatal pelas características da atividade. A enorme pressão, exercida por empresas e clientes, por rapidez nas entregas (Culley, 2002; Fincham, 2006, 2007) leva os motoboys a cometerem imprudências no trânsito. Juntamente com os conflitos com motoristas, ${ }^{3}$ estas contribuem para ocorrências de acidentes fatais ou não (Culley, 2002; Fincham, 2006, 2007), que transformam estes trabalhadores em líderes do ranking nacional de acidentes no trânsito (Marin e Queiroz, 2000). 
Conquanto a ansiedade provocada pelos acidentes ofusque, nos relatos dos atores, os riscos de vitimização por crimes predatórios, ${ }^{4}$ estes constituem uma segunda sobrecarga, uma vez que os motoboys são alvos atrativos de roubo - por conta de seus veículos, encomendas e pertences pessoais - e, ao mesmo tempo, carecem de defesas formais, representadas pelo policiamento estatal ou privado, contra eles (Hobbs et al., 2003). Nesse sentido, a manipulação e o transporte de valores, o trabalho em trânsito, o grande raio de deslocamentos diários (Niosh, 1996), a estigmatização pública ${ }^{5}$ e a desproteção policial geram um déficit crônico de vigilância que eles devem suprir através de defesas informais. Neste ponto, cabe interrogar: Quais são estas defesas? Como elas se adaptam aos diferentes espaços urbanos? Quais as possibilidades e os limites delas para reduzirem as oportunidades de furtos, roubos, agressões físicas?

Esta linha de indagação remete ao papel da vigilância na prevenção de investidas predatórias, visando a explorar as oportunidades criadas pelas atividades rotineiras de indivíduos e grupos sociais (Cohen e Felson, 1979; Felson, 1986). Entendendo que tais oportunidades envolvem a disponibilidade de alvos valiosos e a presença de vigilantes adequados, a falta destes últimos determina a opção para vitimizar com maior freqüência aqueles que estão em desvantagem para responder aos ataques (Cohen e Felson, 1979; Birckbeck, 1984-1985; Beato et al., 2004) ou modificar seus padrões de atividades (Felson, 2006). Segundo esta abordagem situacional do delito, indivíduos que cuidam de uma casa, membros da família, colegas de trabalho, amigos e até estranhos na rua possuem mais condições de atuar como guardiões adequados, porque têm mais probabilidade de estarem presentes nos eventos, do que policiais.

Um dos limites desta teorização é que, embora ela reconheça a importância de laços sociais, interesses comuns e responsabilidades compartilhadas para a vigilância adequada (Cohen e Felson, 1979; Felson, 2006), não há um aprofundamento da discussão acerca das variações desses laços na segurança de indivíduos e grupos em diferentes contextos socioespaciais e legais. Este aspecto, delineado pela teoria do capital social (Coleman, 1988), foi direcionado para explicar os níveis diferenciados de criminalidade em distintos espaços urbanos pela teoria da eficácia coletiva (Sampson et al., 1997). Nessa linha de raciocínio, a teoria das vantagens ecológicas qualifica a influência da eficácia coletiva com base na posição ecológica ou posicionamento espacial dos lugares em termos de oportunidades e meios de controle social de crimes. Ao lado disso, essa teoria chama atenção para dois outros aspectos importantes para o presente estudo: os processos de negociação entre atores legais e ilegais e as expectativas de retaliação das disposições para agir na prevenção do crime (St. Jean, 2007).

Em termos mais específicos, a vigilância compreende defesas, primárias e secundárias, que objetivam tornar os crimes menos atrativos, mais arriscados e mais difíceis. Elas são aplicadas antes ou depois de detectar a presença de ameaças por meio de métodos de ocultação, dissuasão, superação, desestímulo e oposição aos adversários (Felson, 2006). ${ }^{6}$ Ao tempo em que a quase totalidade desse tipo de defesa depende de recursos próprios, individuais e inter-individuais, e, por isso mesmo, se confunde com o que literatura tem denominado de auto-policiamento (self-policing) (Radford, 1987; Sanders, 2005), a defesa secundária simbiótica se dá por meio da mobilização dos recursos de vigilância de outros atores, legais e ilegais (Felson, 2006).

Argumentamos que as (des)vantagens ecológicas dos espaços urbanos estruturam e são, por sua vez, estruturadas pela ação multidimensional dos atores nos planos da defesa individual, inter-individual e inter-grupal. À medida que essas (des)vantagens ecológicas - ou facilidades espaciais dos lugares - para a criminalidade predatória e suas vítimas, atuais e potenciais (St. Jean, 2007), condicionam a demanda e a forma de vigilância adequada, as defesas podem ser pensadas como táticas socioespaciais (Lysaght e Basten, 2003) restritivas e expansivas. Tais táticas estão pautadas na adaptação pragmática às situações, na exploração das possibilidades existentes e, no caso das defesas expansivas, na negociação de vigilância adequada de atores lícitos e ilícitos. Ainda que ambos os tipos de tática sejam complementares, acreditamos que as de caráter expansivo são mais efetivas para a redução das desvantagens ecológicas que atingem os motoboys do que as defesas meramente restritivas. 


\section{Trabalho de campo}

O trabalho de campo foi realizado em 2004 e incluiu 53 entrevistas, subdivididas em 32 entrevistas semi-estruturadas e 21 não estruturadas, e 15 horas de observação direta. Esta enfocou rotina de trabalho de moto-entrega, assembléias e concentrações sindicais, audiências públicas, encontros técnicos e reuniões com policiais de trânsito. Além dos motoboys, foram entrevistados três proprietários de empresas de moto-entrega, o presidente do sindicato da categoria e o comandante da unidade especial de policiamento de trânsito.

Como critérios de seleção de motoboys para a pesquisa utilizamos o tempo de exercício profissional (tempo mínimo de seis meses de exercício e tempo máximo de um ano de afastamento), o tipo de relação de trabalho (trabalhadores informais ou formais, terceirizados ou com vínculos diretos com a empresa contratante) e o tipo de atividade de entrega (trabalhadores de lojas de alimentos, farmácia, autopeças, vendas, correios, documentação e outros, nas proximidades dos estabelecimentos onde eles costumam ficar aglomerados em vários pontos da cidade).

Os contatos com os motoboys foram feitos de três maneiras: abordagens seguidas por entrevistas não estruturadas nas ruas, indicações do sindicato da categoria e indicações de colegas já entrevistados, com base na técnica da bola de neve. As novas entrevistas foram realizadas no carro de um dos pesquisadores ou em centros comerciais, com duração média de uma hora e meia. Tanto os nomes dos entrevistados como os bairros referenciados foram alterados com o intuito de manter sigilo.

Entre os 53 trabalhadores entrevistados, a sistematização dos dados sociodemográficos correspondentes a 32 depoentes evidencia a predominância quase absoluta do sexo masculino, negros-mestiços, com segundo grau completo, casados e com filhos. Apenas seis trabalhadores eram solteiros. Os entrevistados tinham uma idade que variava entre $30 \mathrm{e}$ 38 anos, sendo apenas nove com idade inferior aos 30 anos e seis com idade superior aos 38 anos. $\mathrm{O}$ mais jovem entrevistado tinha 22 anos e o mais velho 49 anos. A totalidade desses motoboys trabalhava com motos próprias e apenas quatro deles possuíam seguros de veículo. Todos residiam em bairros de baixo poder aquisitivo de Salvador. Considerando-se as relações de trabalho, dezessete tinham contrato direto com a empresa, onze eram autônomos e quatro eram trabalhadores terceirizados. Três deles trabalhavam à noite como moto-taxistas.

Quanto aos motoboys vitimizados $(56 \%$ da amostra), dois perderam a moto por furto, oito sofreram tentativas de assalto e oito já tinham sido assaltados. Entre estes últimos, dois foram vítimas repetidas de assalto. Contudo, em vez destes elevados níveis de vitimização causarem sentimentos de impotência (Paes-Machado e Nascimento, 2006), os motoboys entrevistados manifestaram confiança nas virtudes das suas defesas para enfrentar os perigos e as ameaças do dia-a-dia.

\section{Táticas socioespaciais restritivas}

As defesas restritivas, individuais e inter-individuais, visam a evitar interações forçadas (Katz, 1988) com indivíduos e ambientes hostis e, no limite, contra-atacar as ameaças e os perigos advindos daí. Tais defesas são apropriadas para áreas ecológicas, a exemplo de locais de passagem e lugares com rotas de fugas, onde o outro - o infrator está lá - não domina por completo a situação ou pode ser neutralizado por diferentes artimanhas, como: uso de equipamentos contra furtos, imitação de motocicletas velhas, checagem dos endereços dos destinatários, uso seletivo do uniforme de trabalho, realização de entregas em dupla, cuidados especiais com encomendas de maior valor, mudanças previstas e imprevistas de itinerários (fugas) e suspensão das entregas nas áreas ecológicas mais arriscadas.

Além de prestarem bastante atenção aos locais de estacionamento, os motoboys utilizam equipamentos para dificultar furtos de veículos, como alarmes, travas e correntes, chegando a retirar peças dos motores dos veículos para estes não funcionarem. Trata-se de procedimentos que, objetivando aumentar a inércia e reduzir a atratividade do alvo (Cohen e Felson, 1979), são compatíveis com pelo menos dois aspectos importantes. De um lado, a existência de um mercado ilegal de motocicletas e peças roubadas que é alimentado pelo consumo 
predatório (Zaluar, 1994; Neto et al., s.d) dos motociclistas e dos próprios motoboys. No propósito de rebaixar os custos das motos, tais atores estimulam atividades predatórias contra indivíduos e grupos possuidores desses bens (Paes-Machado, 2006). De outro, o fato de a maioria desses trabalhadores, a exemplo de três quartos dos proprietários de veículos no Brasil, não possuir seguro contra perdas totais ou parciais das suas motocicletas, arriscando a perder o emprego, já que, como foi declarado pelos entrevistados, "sem moto [própria] não há trabalho" (Weher, s.d). Tais medidas de precaução são insuficientes, contudo, para impedir que as motocicletas sejam furtadas e carregadas por veículos utilitários, ou mesmo roubadas no trânsito.

Uma segunda medida contra furtos e roubos das motocicletas consiste na redução do valor e da visibilidade relativa da moto mediante a imitação (Felson, 2006) de veículos mais velhos ou gastos. Isto é feito com a colagem de adesivos na carroceria, retirada de peças e conservação da sujeira sobre os mesmos (Neto et al., s.d). O objetivo é depreciar o valor da oportunidade (Birkbeck, 1984-1985) representada pelas motocicletas para que elas não fiquem "visadas" pelos ladrões, mesmo que isto signifique abrir mão, ao menos temporariamente, da distinção social e do narcisismo associados à posse de veículos novos e reluzentes. Em sociedades onde, apesar dos elevados índices de crimes, os membros das classes altas e médias insistem com a ostentação de símbolos de distinção que contribuem para torná-los alvos atrativos, esse bom senso dos estigmatizados motoboys é algo a ser lembrado. Entretanto, e a exemplo do caráter incerto de qualquer defesa, para predadores interessados no desmanche das motocicletas e venda de peças avulsas, tais truques não chegam a ser um impedimento.

Embora a checagem de endereços dos clientes seja comum na atividade de entrega, ela está permeada pela função de segurança (Iafolla, 2004) e tem um caráter proativo contra roubos. Esta checagem é feita a partir do catálogo telefônico, das empresas de telefonia, das consultas aos colegas, das chamadas para localizar endereços, verificando a identidade e vasculhando riscos associados aos usuários (Sanders, 2005). Tal método, porém, pode ser neutralizado por falsos clientes ou imitadores (Gam- betta e Hammil, 2005; Sanders, 2005; Felson, 2006) que, após fazerem pedidos e fornecerem endereços aparentemente corretos, o chamado "trote", assaltam os motoboys:

[...] às vezes a gente também é assaltado em certas entregas que a gente faz que são trotes. Isso é muito freqüente, o cara faz o pedido, dá o endereço certo e quando a gente chega lá, o cara está embaixo esperando a gente pra assal$\operatorname{tar}$ (Edu, 23 anos).

A manipulação da identidade mediante a imitação (Felson, 2006) é uma defesa bastante utilizada no transporte de encomendas mais valiosas. A imitação envolve o uso seletivo de fardas e equipamentos no intuito de reduzir a visibilidade (Lysagth e Basten, 2003; Felson, 2006), evitar a identificação ou ocultar a associação (Sanders, 2005) com estabelecimentos que operam com dinheiro, talões de cheque, cartões telefônicos, tíquetes e outros objetos. Esta prática, contudo, não está isenta de ambivalência. Ao tempo em que os trabalhadores se sentem orgulhosos e mais seguros quando usam fardas e mochilas com logotipos das suas empresas, eles substituem, quando estão fazendo este tipo de entrega, a roupa de trabalho pelo próprio vestuário para se confundirem com outros motoboys e, desse modo, se ocultarem dos agressores (Felson, 2006).

Ora, se esta é uma boa receita para se safar de assaltantes, o mesmo não vale para o público e a polícia. A falta de uniforme alimenta suspeitas e discriminação dos transeuntes contra os motoboys. Quanto à polícia, cuja atuação constitui, em vários aspectos, um risco adicional para esses trabalhadores (Sanders, 2005; Riccio-Oliveira, 2005), por conta da estigmatização da categoria e dos abusos de autoridade, ela pára e revista mais freqüentemente os motoboys não uniformizados, fazendo-os perder tempo e mesmo submetendo-os a arbitrariedades (Riccio-Oliveira, 2005). Vale lembrar que também não é recomendável passar em casa para almoçar com as encomendas, como ainda é hábito entre os motoboys da região analisada.

O trabalho em dupla, do motoboy acompanhado por um conhecido na garupa do veículo é outra forma de defesa grupal (Felson, 2006) contra 
roubos de motocicletas praticados por duplas de motociclistas infratores. Por disporem de veículos velozes, celulares e armas de fogo para cometer crimes e evitar flagrantes, em diferentes lugares e momentos, as ações dessas duplas já foram chamadas de "violência pau de fósforo". Ainda que o motoboy tenha que pagar ao parceiro com recursos do seu próprio bolso, esta prática explora o temor despertado, em muita gente, por duplas de motociclistas e sinaliza os infratores de plantão que ele está preparado para reagir. O trabalho em dupla, porém, apresenta a mesma desvantagem, mencionada antes, de favorecer as suspeitas do público e as abordagens da polícia:

Têm atividades que a gente trabalha de dois, pelo seguinte: eu às vezes, quando estou entregando convite à noite, chamo algum amigo meu, dou um dinheiro a ele, e ele vai comigo entregando... Por que eu faço isso? Pra minha própria segurança. Eu vou ser parado mil vezes [pela polícia], mas eu vou estar seguro também... Porque o ladrão vai pensar que eu sou ladrão, e não vai querer me parar, e não vai me roubar... O bandido que está lá rondando não encosta em mim! (Luis, 30 anos).

Ao lado dessa forma de defesa grupal, os motoboys também recorrem à chamada defesa social emergente (Felson, 2006). Fundada na solidariedade e advinda das condições de trabalho, da estigmatização e da sensação de desproteção e de uma concepção reativa da masculinidade, a defesa social se expressa na formação de grupos de apoio a colegas envolvidos em conflitos nas ruas: "A classe é muito unida e se um motoboy estiver brigando com um motorista, todos vão ajudar" (Renato, 26 anos). Tal defesa faz com que os motoboys sejam particularmente temidos. Embora a defesa social seja comum nas situações de conflito com motoristas, ela não funciona contra ataques violentos e rápidos.

No transporte de dinheiro e encomendas mais valiosas, os trabalhadores empregam métodos de ocultação e despistamento. Afora o desejo de não terem prejuízos, os trabalhadores temem ser responsabilizados (Ewald, 2002; Paes-Machado e Nascimento, 2006) pelos estabelecimentos: receiam ser considerados suspeitos, perderem o emprego e angariarem referências negativas que dificultarão a obtenção de um novo posto de trabalho (RiccioOliveira, 2005).

Essa linha de defesa manifesta-se no cuidado com a manipulação e o transporte de dinheiro subatividade de entrega mais perigosa segundo os trabalhadores - dentro e fora das agências bancárias e estabelecimentos comerciais. Nas agências, eles buscam não chamar atenção de predadores que costumam espreitar a movimentação dos saques para roubar vítimas potenciais, como os motoboys ou outros clientes, quando eles saem dos estabelecimentos, de acordo com uma modalidade de crime conhecida como "saidinha bancária". Os motoboys que trabalham com estas encomendas também limitam, com o consentimento de seus patrões, o volume das retiradas e entregas de dinheiro. Tal prática, que multiplica os trajetos, fragmenta e dilata o tempo de cumprimento das tarefas, seria mais complicada se a remuneração da força de trabalho e o consumo de combustível fossem mais elevados. ${ }^{7}$ O terceiro procedimento consiste em distribuir os valores em vários compartimentos, como bolsos, mochilas etc. para evitar perdas totais caso haja um assalto. Esta e outras receitas estão resumidas no seguinte trecho:

Muitas vezes quando vou entregar valores, vou com as encomendas em mochilas e mais um colega na garupa para despistar; também procuro sair em horários diferentes para não ficar muito visado. Também não uso a camisa com o logotipo nem a mochila da empresa (Paulo, 49 anos).

Um dos limites desse tipo de defesa, ignorado pela literatura especializada (Felson, 2006), deriva de um dos mais temíveis riscos apresentados pelo trabalho de moto-entrega: a infiltração predatória dos estabelecimentos por infratores que fornecem informações para seus comparsas roubarem os motoboys. Trabalhar com o inimigo sem saber é um dos caminhos mais curtos para o inferno. Contra isto apenas o sigilo entre colegas de trabalho e a tentativa de desestimular, por meio de várias artimanhas, os infratores. 
Do mesmo modo que outros grupos que se deslocam em zonas de risco (Lysaght e Basten, 2003), os motoboys também modificam suas rotas de deslocamento para não se tornarem alvos fáceis. Tais modificações envolvem tanto as mudanças previstas de itinerários para alterar as atividades rotineiras (Felson, 2006) ou reduzir a previsibilidade de tempo e lugar de deslocamento (Lysaght e Basten, 2003), como as mudanças imprevistas para escapar de encontros perigosos e confrontos armados (Linger, 1992; Paes-Machado e Levenstein, 2004).

Se o uso de carros permite aos motoristas superar riscos de violência associados às divisões espaciais (Lysaght e Basten, 2003), isto não se aplica ao emprego de veículos para atividades profissionais (Gambetta e Hammil, 2005). No caso dos motoboys, por melhores que sejam a mobilidade e a visão proporcionadas por suas motocicletas, eles transportam bens cobiçados e seguem rotinas mais rígidas e identificáveis do que os motoristas não profissionais (Lysaght e Basten, 2003). É assim que, quanto maior o limite para modificar esta rotina, por causa dos horários comerciais, e quanto maiores os riscos de infiltração criminosa, mais imperiosa é a necessidade de variar os itinerários ou até transferir, em acordo com os estabelecimentos, o transporte das encomendas visadas para carros.

Nestes casos [de assaltos], eles já sabem o que a gente leva. Isto aconteceu com um colega meu da empresa. Aí eu tive que mudar todo o meu roteiro e os meus horários... cada dia eu ia por um lugar diferente, num horário diferente, às vezes não levava o malote... às vezes eu levava só documentos, [o] dinheiro e cheque ia de carro, porque os caras realmente sabiam tudo. $\mathrm{O}$ malandro deu placa de moto, as cores da moto, a descrição de cada um da gente, o que a gente levava, o horário certinho, tudo... muitas vezes tem gente da própria empresa envolvida, principalmente pra quem trabalha em banco (Edu, 23 anos).

A competência espacial, ${ }^{8}$ a sabedoria de rua (Anderson, 1990) e o conhecimento sofisticado da ecologia urbana (St. Jean, 2007) dos motoboys permitem rastrear, ao modo de radares ultra-sensíveis, sinais quase imperceptíveis de alteração no ambiente, registrando movimentos de motociclistas suspeitos e orientando mudanças imprevistas de itinerários. O lema aqui é 'não esperar para ver:

A gente já desconfia quando vê dois numa moto... qualquer coisa fora do padrão, qualquer coisa que seja suspeita você realmente tem que mudar o seu itinerário, tem que entrar em algum lugar, fingir que parou, que vai falar com alguém, que vai pedir uma informação... fazer qualquer coisa pra poder evitar o assalto... (Carlos, 30 anos).

Pode-se verificar neste trecho como o estado de alerta aos perigos e às ameaças que brotam das ruas potencializa a acuidade perceptiva como meio de antecipação, tomando a forma de um habitus que já fez com que esses trabalhadores fossem chamados de ases do asfalto (Riccio-Oliveira, 2006).

A prioridade é desencorajar os atacantes e mobilizar defesas de outros atores, seguranças ou policiais, para inibi-los (Felson, 2006) por meio de um verdadeiro jogo de esconde-esconde. Ao observarem motos com dois ocupantes na proximidade dos semáforos, onde acontecem muitos assaltos de motoboys (Riccio-Oliveira, 2005) e de condutores de outros tipos de veículos, eles fazem bruscas e arriscadas manobras de trânsito e de itinerário, reduzindo ou aumentando a velocidade para não parar junto a tais motociclistas. Outras táticas socioespaciais adotadas nessas situações são: entrar em ruas secundárias, aproximar-se de um aglomerado de pessoas, parar simulando buscar informações, ir para a outra extremidade da via e avançar o sinal (Riccio-Oliveira, 2005). Em deslocamento, os motoboys também evitam pilotar próximos a duplas de motociclistas suspeitas ou prestar socorro, por mais solidários que sejam com seus colegas (Neto et al., s.d), assim como procuram se aproximar, à menor desconfiança de que estão sendo seguidos, de locais onde haja seguranças ou policiais. Além de aumentarem os riscos de acidentes, essas manobras arriscadas nem sempre conseguem esquivar-se de motociclistas delinqüentes que, além de pilotarem motocicletas mais velozes, também possuem um conhecimento sofisticado da ecologia urbana 
ou tiram proveito da noite para emboscar os motoboys, às vezes com arames estendidos nas ruas.

No caso de serem surpreendidos por atacantes, só resta a esses trabalhadores a submissão ou a tentativa de fuga (Conklin, 1972; Wright e Decker, 1997; Matthews, 2002; Felson, 2006). O que determina a opção pela fuga, seja ela bem ou mal-sucedida, é o receio de que as empresas os responsabilizem, levando os motoboys a assumirem atitudes precipitadas para defender os produtos conduzidos (Riccio-Oliveira, 2005), ou mesmo a idéia de que têm chances de escapar ilesos ou ainda a reação emocional inesperada (Paes-Machado e Levenstein, 2004). Vejamos então dois exemplos de fuga numa situação de encontro perigoso. No primeiro, o fato de os infratores demonstrarem pouco poder de dissuasão (Conklin, 1972; Wright e Decker, 1997; Matthews, 2002) fez uma dupla de motoboys desobedecer a ordem de parar, empreendendo uma fuga que poderia resultar em tragédia. No segundo, o mesmo motoboy empreendeu duas fugas arriscadas da mesma dupla de assaltantes. Se a primeira fuga foi frustrada pelo disparo de um tiro, na segunda ele se jogou, na falta de rotas alternativas e aparentemente tomado pelo desespero, em uma vala com a moto.

A fuga também é a principal defesa quando eles adentram, inadvertidamente, uma área ecológica de risco transformada em campo de batalha entre grupos de infratores ou entre estes e as forças policiais. Diante de episódios perigosos como estes, os motoboys buscam um refúgio no local e/ou retornam à empresa sem entregar a encomenda, como veremos a seguir.

\section{Suspensão das entregas}

O comportamento de risco não é uma ação individual ou isolada, mas é modelado socialmente pelas relações de poder e negociação entre atores desigualmente dotados para impor, aceitar ou evitar condutas consideradas arriscadas (Rhodes, 1997). É assim que, em meio às dinâmicas complexas que envolvem a existência e as reações ao risco (Best, Lukenbill, 1982), é preciso atentar para os processos de resistência contra a imposição de condutas que ultrapassam o patamar de tolerância de indivíduos e grupos.
No contexto aqui estudado, chama atenção o comportamento dos trabalhadores de suspender as entregas em área ecológicas onde foram alvo de investidas ou ameaças predatórias. Entre os vários critérios de tipificação dessas áreas, um fator decisivo é a inexistência de lideranças criminosas que possuam domínio territorial e forneçam créditos de proteção aos motoboys.

Se com respeito às demais táticas socioespaciais há um consenso entre motoboys e estabelecimentos acerca da sua validade, isto não acontece com a suspensão das entregas. Por ameaçar o fluxo de encomendas e colocar em xeque o precário equilíbrio entre condutas de aceitação e aversão a riscos, a suspensão das entregas é malvista pelos estabelecimentos. Uma vez que a base do negócio é garantir acima de tudo a continuidade das entregas para não perder clientes, não importa os meios e os sacrifícios realizados para isto. A postura temerária de arriscar a sofrer ataques predatórios é reforçada pela ameaça de demissão. Daí que, apesar de a grande maioria dos entrevistados ter expressado o desejo de interromper suas atividades nas áreas ecológicas de alto risco, a tendência geral é buscar vencer seus medos e continuar o trabalho. Esta postura, no entanto, pode mudar conforme a gravidade dos perigos e ameaças, levando esses trabalhadores a suspenderem velada ou abertamente a entrega de encomendas.

Na linha da chamada resistência cotidiana, os motoboys criam mentiras plausíveis, como, por exemplo, a não identificação dos endereços de clientes por causa do caráter acidentado e irregular do casco urbano, para não entrarem em rota de colisão com as empresas (Scott, 1990). "Quando tem local perigoso eu invento uma desculpa. Eu digo que não achei a casa e a empresa liga mandando o cliente ir buscar na loja" (Marcelo, 22 anos). Em contraponto com este procedimento velado, vários entrevistados são mais assertivos: "Eu me recuso a fazer entrega em local perigoso. A empresa não assume atitude nenhuma" (Zivaldo, 28 anos). Sem ignorar o poder de barganha diferenciado de indivíduos e grupos dentro da ocupação, esta postura deve ser vista como uma forma de resistência à lógica de desresponsabilização ou descaso dos estabelecimentos com os riscos de vitimização de seus empregados 
(Paes-Machado e Nascimento, 2004). Este é o caso do entrevistado, já mencionado anteriormente, que após ter sofrido uma ameaça de assalto resolveu suspender as entregas na área onde aconteceu o fato.

Quanto à posição dos estabelecimentos, fatores como os prejuízos resultantes de roubos, a resistência continuada dos trabalhadores e a visibilidade pública negativa das áreas ecológicas de alto risco podem levá-los a concordar com as interrupções de entregas e se inclinarem para medidas de maior segurança. Em uma linha proativa de gerenciamento de riscos, algumas empresas, a exemplo de cadeias de pizzarias, farmácias, entre outras, não somente cortam as entregas em locais mais inseguros, como também elaboram mapas de risco informatizados dos pontos quentes (hot spots), algumas vezes representados com caveiras, para orientar a decisão de entrega.

Infortunadamente, essas iniciativas são ou tendem a permanecer marginais no conjunto da atividade. Em primeiro lugar, por causa das grandes diferenças entre os estabelecimentos quanto às estratégias de venda, gerenciamento de riscos e disponibilidade de tecnologias de segurança. Em segundo, porque a recusa de muitas entregas faz com que os motoboys relaxem suas defesas e aceitem fazer, pressionados pela sobrevivência, entregas em áreas tão ou mais perigosas do que as que foram recusadas (Gambetta e Hammil, 2005).

Um balanço dessa e das demais táticas socioespaciais restritivas analisadas revela a diversidade, a flexibilidade e a capacidade de adaptação às (des)vantagens ecológicas representadas pelos perigos e ameaças percebidas em determinados espaços urbanos. Mostra também como, apesar do enorme ônus para os trabalhadores, essas defesas estão comprometidas por seus efeitos antecipados ou não, e podem gerar efeitos diferentes dos esperados (Sanders, 2005). Esta pontualidade e imprevisibilidade das defesas restritivas contrasta com a maior continuidade e previsibilidade das defesas táticas socioespaciais expansivas.

\section{Táticas socioespaciais expansivas}

Conquanto a literatura especializada sobre controle da criminalidade saliente o papel das defesas restritivas e da vigilância prestada por atores legais (Shapland e Hall, 2005; Felson, 2006), o mundo social da atividade de moto-entrega, em espaços urbanos como o de Salvador, aponta para direções menos ortodoxas. Estas envolvem interações completas (Hannerz, 1980) e negociações com atores ilegais para gerenciar crimes aleatórios (St. Jean, 2007) ou se defender de predadores avulsos. Essa negociação para lograr vigilância adequada de atores ilegais está muito presente em áreas ecológicas onde o outro - o infrator está aqui - possui domínio territorial e limita a circulação de pessoas, bens e serviços mediante autorizações especiais (Fonseca e Brito, 2008) ou créditos de proteção.

Os créditos de proteção fornecidos aos motoboys pelos "caras" compatibilizam a manutenção da normalidade do fluxo de encomendas com o domínio territorial (Tapparelli, 1996). Se para os motoboys é complicado suspender as atividades de entrega, aos membros das quadrilhas tampouco interessa sustar os recebimentos de encomendas, visto que tanto eles como os moradores dependem delas para seu abastecimento. Por sua vez, o controle territorial recomenda limitações ao acesso e à circulação de pessoas estranhas às localidades, em especial, de condutores de veículos, como carros e motocicletas, para se defenderem de ataques. Contra esses, "os caras" possuem dispositivos eficientes de observação, comunicação, poder de fogo e, em algumas situações, toque de recolher.

Do ponto de vista dos trabalhadores, os acertos para recebimento de créditos de proteção constituem uma iniciativa corajosa e, ao mesmo tempo, uma rendição pela assimetria das relações entre os atores e natureza das concessões feitas. Esses acertos também podem ser vistos como uma ruptura do princípio das defesas restritivas, individuais e inter-individuais, pelo fato de os motoboys passarem a depender da provisão de vigilância pelos "caras". Pensando neste e em outros exemplos parecidos, pode-se afirmar que a segurança não é uma propriedade social cumulativa que permite somar todos os meios desejáveis para lidar com os perigos e as ameaças. A busca de segurança também envolve subtrações resultantes de incompatibilidades de escolhas e compromissos não desejados, mas incontornáveis, que emolduram as atividades e as situações concretas de indivíduos e grupos. 
A permissão para entrar em áreas controladas por quadrilhas passa pela aceitação de exigências relativas à liberdade de ir e vir, ao uso de equipamentos de segurança e à condução de motocicletas, cujos usos delituosos são bem conhecidos por todos. Conseqüentemente, os motoboys não devem circular com capacetes e motocicletas, devem se submeter ao pagamento de extorsões e, em certos casos, transferir a entrega de encomendas para motoboys residentes ou conhecidos nestas áreas.

Despir-se do seu principal instrumento de proteção individual - o capacete - é a primeira exigência a ser atendida. A exemplo do que sucede nas portarias de estabelecimentos financeiro-comerciais e prédios residenciais, os motoboys devem retirar seus capacetes nestas áreas ecológicas (Culley, 2002; Riccio-Oliveira, 2005). Os riscos de acidentes, de multas de trânsito ou os inconvenientes causados pela chuva são considerados menos graves do que o descumprimento de uma regra obrigatória de circulação. Ironicamente, o artefato que garante proteção a uns é visto como uma ameaça a outros, por favorecer, tal como as máscaras, o anonimato perigoso dos seus portadores (Huggins et al., 2006). No caso dessas áreas, a justificativa, não de todo infundada dos "caras", é que sob o capacete de um motociclista pode estar um inimigo em potencial, um policial ou um delinqüente rival.

Apesar dessas limitações, vários entrevistados mencionaram a flexibilidade das quadrilhas com respeito aos entregadores de medicamentos. Elas não querem se responsabilizar pela falta de medicação aos doentes porque podem ficar com a imagem prejudicada junto aos moradores das localidades. Após checarem as credenciais, revistarem as mochilas e verificarem os documentos de identidade, eles liberam o acesso ao local e até auxiliam os motoboys a encontrar o endereço desejado:

Simplesmente tem que esperar que eles venham para saber qual é o problema... você abre a sacola e mostra que está trabalhando. Quando a gente mostra que está trabalhando a coisa fica mais fácil. Principalmente quando é remédio... é uma coisa mais fácil de trabalhar porque eles respeitam muito quando é remédio... E aí eles liberam a gente numa boa, chegam a levar na casa e tudo, chegam a ajudar... Eles chegaram a me ajudar uma vez, eu procurando um endereço de madrugada... mas dava medo! (Valdir, 31 anos).

O pagamento de extorsão para circular, ter acesso ou permanecer nos espaços urbanos é um padrão difundido nas cidades brasileiras (Paes-Machado e Levenstein, 2004; Paes-Machado e Noronha, 2002). Os agentes das extorsões são, entre outros, mendigos, crianças em situação de rua, vendedores ambulantes, guardadores informais de automóveis, vigilantes clandestinos e quadrilhas de bairros. Ao lado da pressão do emprego (e do subemprego), a compreensão alargada do fenômeno envolve dois determinantes sociolegais: a normalização da intimidação para lograr vantagens monetárias e o descaso das autoridades públicas com respeito a esse tipo de ilegalidade. No que se refere às quadrilhas de bairro, estas se valem da sua reputação de violência (Volkov, 2002) para cobrar proteção ao indivíduo e a grupos que vivem ou circulam em áreas que estão sob seu controle. Afora ser uma renda complementar, as extorsões simbolizam e reforçam o domínio territorial.

Com efeito, nas áreas ecológicas de risco aqui referidas, a liberdade de ir e vir depende do pagamento do "pedágio" (toll) ou forma de renda de proteção (Volkov, 2002), em dinheiro ou em espécie - tíquetes de alimentação e vales transporte etc. Muita gente já deixa separado um valor para isto (Gambetta e Hammil, 2005; Paes-Machado e Levenstein, 2004), o chamado "dinheiro do ladrão". Qualquer tentativa de não pagamento é tomada como uma ofensa e como pretexto para os agressores - seguindo a conhecida expressão de 'ou dá ou desce' - intensificarem a pressão, roubarem os pertences e até agredirem as vítimas:

Às vezes a gente está indo visitar os clientes e recebe aquela abordagem: "Me dê um dinheiro aí!” Isso pra poder passar. Às vezes armados [...] A verdade é essa, entendeu? Aí às vezes a gente não conseguia dizer que não, porque eles só esperam que a gente diga não pra tomar aquilo como ofensa, e aí vai até mesmo lhe assaltar, tomar tudo que você tem... Então é até melhor dar, entendeu? Pelo menos já ficava até 
um pouco mais conhecido na área, pra quando tiver que voltar (Ari, 30 anos).

Tais extorsões estão de tal modo integradas à rotina desses trabalhadores que são vistas de modo positivo, como um meio de ficarem conhecidos, ganharem a simpatia e facilitarem suas atividades. Nessa condição, os pagamentos poderão ser suspensos, relaxados ou mesmo substituídos por favores. Uma vez conhecido, o motoboy passa a merecer uma "consideração" pessoal que opera como crédito de proteção contra investidas de terceiros, elementos da quadrilha ou predadores avulsos:

Logo quando eu comecei a trabalhar aqui embaixo, eu não conhecia ninguém, então eu passava e os meninos: "Me dá um dinheiro pra eu comprar maconha, me dá um real pra inteirar a maconha aí...”. Eu não conhecia muita gente, aí eu dava com medo de ser assaltado... Eu via eles fumando maconha, ficava com medo, então dava... Mas agora que eu já conheço eles, todos já me conhecem, aí agora eu não dou mais... também eles não pedem mais... e também se ver alguém mexer comigo, eles já não deixam... É que eu já conheço todos eles, já fiz amizade com todo mundo. Meninos, pessoas adultas, todos gostam de mim... (Pedro, 31 anos).

Conforme este depoimento, os contatos iniciais do motoboy com a quadrilha pavimentaram o caminho para uma relação proveitosa, e o que poderia se converter em extorsão continuada (Volkov, 2002; Misse, 1997; Cano e Iooty, 2008) resultou na aquisição de vigilantes capazes de reduzir a vulnerabilidade do trabalhador.

Por fim, quando "os caras" só permitem o acesso de trabalhadores conhecidos ou de sua confiança, os motoboys recusados informam seus estabelecimentos e buscam, sob a orientação destes, identificar e contatar trabalhadores adequados à tarefa. A confiança proveniente dos laços de conhecimento substitui os demais mecanismos de credenciamento de proteção e até os pagamentos monetários, contribuindo para estabilizar transações e render benefícios aos atores envolvidos: "Escapei várias vezes porque conheço os caras de onde eu moro e eles não me assaltavam. Quando via que iam me assaltar, eu cumprimentava e 'aí velho', então não me roubavam porque sou da área" (Cassandro, 22 anos). Aqui, como em muitos domínios sociais, as relações informais, iniciadas de modo casual ou a partir das recomendações de terceiros, constituem uma credencial (Monaghan, 2002) mais eficiente para lograr vigilância adequada do que qualquer canal burocrático-legal.

\section{Redes sociais de vigilância}

Considerando o déficit crônico de vigilância dos trabalhadores de moto-entrega, as expectativas e as obrigações criadas e consolidadas por meio de laços sociais (Coleman, 1988) com os moradores também cumprem um importante papel na provisão de segurança a eles. Ainda que não se possa exagerar a influência destas expectativas e obrigações na prevenção do crime - em especial de crimes considerados sérios como assaltos e tráfico de drogas -, ela é suficiente para prover vigilância a atividades como a entrega de encomendas, que não incorrem em riscos de retaliação por parte de elementos criminosos (St. Jean, 2007). Nessa linha, o apoio dos moradores funciona como um amortecedor (buffer) ecológico mais eficiente do que o crédito de proteção concedido pela gangues de bairro.

A mobilização desse capital social, incluindo a familiaridade com o espaço, se manifesta na obtenção e na transmissão de informações, provisão de vigilância pessoal e patrimonial e auxílio, direto e indireto, às entregas em áreas onde os motoboys estão impedidos de realizar seu trabalho. As redes sociais de vizinhos é a principal fonte de informação para mapear riscos, avaliar ameaças e conhecer as regras de circulação estabelecidas como, por exemplo, a exigência, já examinada antes, de os motoboys não usarem capacetes. Este foi o caso de um motoboy que trabalha como fiscal do serviço de limpeza pública e que, ao entrar em um bairro inseguro, foi alertado por um transeunte a retirar o capacete para não ser confundido com um inimigo, evitando assim, porventura, um desfecho trágico.

Rapaz, eu vou lhe falar uma coisa, quando você entrar no bairro Q tire o capacete. Você já foi 
confundido ali dentro com polícia, eu que disse aos caras [delinqüentes] que você não era polícia. Você já soube que teve gente que já quis até meter bala em você lá dentro? E eu não sabia de nada... Ele disse: "Quando você entrar no Bairro $\mathrm{X}$ tire o capacete e quando você me vê se aproxime e vá conversar comigo". Aí eu fiz isso, ele me apresentou à malandragem e relatou aos caras o que conversou comigo. Eles disseram: "Você pulou uma fogueira aqui dentro, estava tendo a maior guerra aqui, os policiais estavam encarnando [fazendo operações], e você pra lá e pra cá com essa moto aí... Já teve gente que teve vontade de meter a bala em você"... Você veja, eu poderia estar morto sem saber por que! (Mateus, 33 anos).

Dadas estas e outras restrições impostas pelas quadrilhas, tudo seria mais difícil sem a vigilância patrimonial igualmente proporcionada pelos vizinhos (St. Jean, 2007). É assim que, no que se refere ao impedimento de circular de motocicleta, os trabalhadores também recorrem aos moradores da sua confiança para guardar seus veículos e pertences pessoais enquanto realizam os roteiros de entrega a pé, o que prolonga o tempo gasto na tarefa, causa prejuízos financeiros e desgaste físico-psicológico.

No bairro Q a rota tinha que ser toda a pé mesmo. Só ia de moto até o início, pois esse era o único bar onde eu podia largar a moto, porque eu já tinha uma certa confiança com o dono do estabelecimento. Eu deixava a moto lá, chamava por Deus e ia fazer a rota... Quer dizer, uma rota que de moto eu acabava em uma hora, mas como eu tinha que fazer a pé... na cara e na coragem mesmo... eu gastava, mais ou menos, umas três horas, três horas e meia de relógio... (José, 34 anos).

Ao lado desse apoio logístico, os trabalhadores contam com a ajuda dos vizinhos para a redistribuição das encomendas (Fonseca e Brito, 2008). Por mais banal que pareça, esta redistribuição opera como uma socialização informal de riscos, responsabilidades e tarefas que modifica a forma da atividade e redimensiona o papel dos motoboys na aproximação dos domínios da oferta e da demanda. Seguindo esta lógica de flexibilização da cadeia de entregas, os motoboys delegam parte de suas atividades a moradores, comerciantes e lideranças locais, que passam a atuar como pontes de ligação com clientes e vigilantes patrimoniais. Assim, os moradores assumem, de modo voluntário, tarefas típicas dos motoboys, a exemplo da identificação e dos contatos com clientes, guarda e entrega de encomendas. Para os trabalhadores, ficar na retaguarda dos moradores enquanto esses assumem encargos da distribuição garante a efetivação das entregas, poupa tempo e evita, ao modo de um amortecedor, ataques predatórios.

No bairro $\mathrm{M}$ tem uma escola que a gente não pode ir. A gente tem que entregar o material da escola à diretora de uma outra escola, porque tem uma professora que todo dia à tarde vai até lá... aí a gente dá uma quantidade maior dos folhetos e a professora pega e faz esse trabalho pra gente... leva lá (Luis, 30 anos).

Isso também acontece para as encomendas que necessitam de comprovante de recebimento como, por exemplo, cartas registradas. Como as experiências de colegas assaltados desaconselham entregas diretas, os trabalhadores limitam-se a transmitir recados para os destinatários irem buscar suas encomendas na sede do estabelecimento, o que é mais uma inovação nessa atividade (Culley, 2002; Fincham, 2006, 2007; Wehr, s.d).

No bairro Q tem uma associação de moradores onde deixo as correspondências normais. Quando é carta registrada, deixo um bilhete avisando para o cliente ir buscar na agência. Os Correios não fazem a entrega [direta ao cliente] porque muitos motoqueiros já foram assaltados [...]. Se nós formos [entregar], iremos ficar tomando informações e corremos o risco de sermos assaltados (Edvaldo, 43 anos).

Mas isso não esgota a socialização de riscos pela flexibilização das entregas, uma vez que os destinatários e seus conhecidos também entram no jogo. Se nas sociedades contemporâneas indivíduos e grupos não medem esforços para participar do consumo, o mesmo se aplica ao consumo mediante 
entregas no contexto de grandes cidades, como Salvador. No caso dos moradores das localidades aqui mencionadas, entre serem cortados das listas dos estabelecimentos por residirem em áreas arriscadas, de um lado, e fazerem sacrifícios, como esperar mais tempo ou se deslocar para recolherem as encomendas, de outro, eles preferem a segunda opção. Tais acertos, feitos por telefone ou com a mediação de terceiros, versam sobre a definição de pontos físicos de entrega satisfatórios, sob a ótica da segurança e da distância, ou de pessoas nas mãos das quais os destinatários deverão buscar seus produtos - lojas, sedes de associação de moradores e até mesmo representantes de órgãos públicos.

Por essas razões, reafirmamos que a negociação e mobilização dos recursos de vigilância adequada, de atores externos ao grupo (out-group), torna os resultados das táticas socioespaciais expansivas mais contínuos, previsíveis e efetivos para evitar ataques predatórios do que os das táticas socioespaciais restritivas, limitadas aos recursos individuais e interindividuais do grupo (in-group).

\section{Conclusões}

Neste trabalho, acerca das soluções engenhosas e defesas informais múltiplas dos trabalhadores de moto-entrega contra crimes predatórios, discutimos as possibilidades e limites de eficácia dessas defesas para a redução das oportunidades atrativas para esses crimes.

Para comprovar a pertinência deste foco, encontramos, entre os motoboys entrevistados, uma dupla, simultânea e imbricada jornada de trabalho: a primeira relativa ao cumprimento das obrigações profissionais e a segunda voltada para a redução das oportunidades de vitimização resultantes dessas obrigações. Além de esta segunda jornada implicar esforços adicionais, prejuízos profissionais e financeiros não compensados pelos contratadores e representar, portanto, uma forma perversa de auto-exploração e precarização das relações de trabalho no setor de serviços -, ela possui particularidades que estão no cerne de alguns debates atuais em torno da prevenção do delito (Felson, 2006; St. Jean, 2007).
Tendo em vista a centralidade do conceito de espaço nos estudos a respeito do crime, parte desse debate aborda as defesas ligadas ao uso, organização e reconhecimento dos espaços urbanos pelos autores e pelas vítimas, potenciais e atuais, de delitos (Cohen e Felson, 1979; Sampson et al., 1997; St. Jean, 2007). Nesta linha e ao contrário das visões normativas e estatistas hegemônicas, o nosso argumento realçou o significado das defesas informais para a provisão de vigilância adequada aos trabalhadores. Dentro de uma visão alargada do policiamento - como instrumento de manutenção de arranjos coletivos desejáveis e indesejáveis, ilegais e legais -, essas defesas fazem parte do que vem sendo categorizado como autopoliciamento (self-policing) (Radford, 1987; Sanders, 2005).

Ao levar em conta as referências espaciais que influenciam nas oportunidades atrativas para os crimes, classificamos essas defesas informais múltiplas em táticas socioespaciais restritivas e táticas socioespaciais expansivas. Primando pela sensibilidade, potencial de cobertura e complementaridade, essas táticas dependem da ação criativa dos sujeitos para responder às (des)vantagens ecológicas, dos espaços urbanos, em suas atividades. É assim que, as defesas socioespaciais restritivas são apropriadas para áreas onde, a exemplo de locais de passagem e lugares com rotas de fugas, o outro - o infrator está lá - não domina por completo a situação ou pode ser neutralizado pelas artimanhas dos trabalhadores. Por sua vez, as táticas socioespaciais expansivas são empregadas em dois outros tipos de espaços: áreas onde o outro - o infrator está aqui é capaz de administrar, pelo domínio territorial, o acesso e circulação (Brito e Fonseca, 2008) de pessoas, bens e serviços e, em terceiro lugar, em áreas onde o infrator também está aqui, mas disputa o domínio territorial com outros infratores ou com as forças policiais.

Ao lado dessas características criminogênicas, a eficácia coletiva ou a capacidade das redes de moradores de prover vigilância, no segundo e no terceiro tipo de espaço urbano, faz uma grande diferença para a validade e o sucesso das defesas contra o crime (Sampson et al., 1997). Nessa perspectiva, os nossos achados relativos à negociação de práticas espaciais com possíveis atacantes (Lysaght e 
Basten, 2003), à fluidez de limites (Ruggiero e South, 1997; Misse, 1997) e aos acertos entre atores legais e ilegais para evitar crimes aleatórios (St. Jean, 2007) evidenciaram a existência de uma complementaridade de ações entre os mesmos, a qual remete ao conceito de defesa simbiótica (Felson, 2006).

Embora não tenhamos estudado as quadrilhas de bairros, a análise dos relatos dos motoboys, bem como os resultados de outros estudos nos permitiram verificar que elas jogam um papel positivo na segurança dos motoboys. Isso sucede quando as quadrilhas possuem outras prioridades delituosas a exemplo do tráfico de drogas e da extorsão continuada -, não enxergam ameaças ou extraem vantagens da oferta de proteção (Misse, 1997; Cano e Iooty, 2008), Por mais oposta que seja às concepções sustentadas pela justiça criminal e por algumas teorias criminológicas, esta provisão é coerente com uma realpolitik da rua que aconselha prestar mais atenção à micropolítica das (des)vantagens ecológicas do que aos códigos legais e às políticas de segurança. Nas agendas do dia-a-dia e fazendo uso da máxima de que é "melhor um pássaro na mão do que dois voando", a prioridade dos demandantes de vigilância é a boa vizinhança, a construção de um modus vivendi (Paes-Machado e Noronha, 2002) e a obtenção, mesmo que mediante um preço, de créditos de proteção "dos caras" que ditam os códigos de acesso, circulação e permanência nos seus espaços de atividades.

Quanto ao papel de destaque das redes de moradores na segurança dos motoboys, este é consistente com as teorias que tratam da influência positiva dos laços sociais (Coleman, 1988) e da eficácia coletiva (Sampson et al., 1997; St. Jean, 2007) nas condições de segurança, bem como na disponibilidade de vigilância adequada (Cohen e Felson, 1979) para a prevenção de crimes. Cabe salientar, porém, que no contexto de Salvador, e provavelmente de outras cidades brasileiras, essa influência positiva assume um caráter generalizado e difuso que destoa dos padrões anglo-americanos mais contidos que norteiam essas teorias. Nesse sentido, a situação desses atores brasileiros contrasta com a de trabalhadores vulneráveis do setor de serviços de países do hemisfério norte-ocidental (Gambetta e Hammil, 2004; Sanders, 2005), cuja menor disponibili- dade desse tipo de capital - pela maior auto-suficiência dos indivíduos (Coleman, 1988; DaMatta, 1985; Barbosa, 1992) - faz com que contem apenas com as próprias forças e, eventualmente, com as do policiamento estatal para se defender.

Uma síntese geral dos resultados evidencia a relevância das táticas socioespaciais expansivas para a prevenção do delito: a propriedade destas táticas de criar amortecedores (buffers) ecológicos ou redutores de perigos e ameaças aos motoboys, mediante a negociação e mobilização de vigilância de quadrilhas e redes de moradores, que, pelo domínio ou familiaridade territorial, podem fazer com que sejam concretizadas ou evitadas essas ameaças.

Por fim, apesar do caráter preliminar deste trabalho, acreditamos que ele suscite novas investigações sobre as variações ecológicas da criminalidade e do controle social em espaços urbanos - em particular, os habitados pelas classes populares que, apesar das evidências contrárias, continuam sendo vistos como homogêneos (Machado da Silva, 2008). Ao lado disso, esta pesquisa pode contribuir para discussões mais aprofundadas de métodos informais que - inspirados na máxima de que a melhor defesa é o ataque - investem no capital social/eficácia coletiva e na negociação de vigilância com distintos grupos, para melhorar a segurança dos trabalhadores do setor de serviços, garantir o fluxo de entregas de encomendas e resistir aos efeitos perversos dos crimes predatórios sobre as condições de vida e trabalho das classes populares urbanas.

\section{Notas}

1 Estima-se que só em Salvador existiam cerca de 7 mil motoboys circulando pelas ruas em 2005, enquanto em São Paulo o número atingia 160 mil no ano de 2000.

2 Diferentemente de outras atividades em que o empregador fornece os instrumentos de trabalho, na atividade de moto-entrega a maior parte das empresas exige que o trabalhador possua seus próprios equipamentos (Wehr, s.d). As relações de trabalho são o contrato formal direto com uma empresa principal, a terceirização, o trabalho autônomo e o chamado trabalho free-lancer. A jornada de trabalho divide-se em quatro etapas: espera e recebimento da encomenda, 
deslocamento no trânsito e entrega da encomenda (Oliveira, 2003; Riccio-Oliveira, 2005), sendo que as vitimizações por acidentes e crimes se concentram nas etapas 3 e 4.

3 Estes conflitos resultam das diferenças técnicas entre motocicletas e automóveis (Riccio-Oliveira, 2005) e das condutas de ambos os grupos de condutores de veículos. As condutas dos motoristas estão relacionadas com a frustração pela redução da automobilidade e o incômodo causado por motociclistas que não obedecem às mesmas regras de trânsito que eles (Fincham, 2006, 2007). Por sua vez, os comportamentos dos motoboys resultam de um estilo de condução assertivo e agressivo e de uma cultura ocupacional que valoriza os perigos diários e as infrações de trânsito (Ficham, 2006, 2007; Wher, s.d). Entre os motoboys entrevistados, por exemplo, as principais explicações para suas imprudências foram a já mencionada pressão pela rapidez nas entregas e gosto da excitação ou "adrenalina” produzida pela velocidade.

4 Conforme Felson: " $\mathrm{Na}$ ecologia do crime o termo 'crime predatório' tem um significado não culinário, remetendo a agressões nas quais uma pessoa toma ou danifica a pessoa ou propriedade de outra, que não é uma co-participante neste crime ou vítima repetida deste agressor" (2006, p. 351, tradução nossa).

5 Os motoboys são demonizados e criminalizados por suas condutas nas ruas (Culley, 2002; Fincham, 2006, 2007; Wehr, s,d; Oliveira, 2003; Riccio-Oliveira, 2002, 2005), assim como pelos delitos violentos (e transações com drogas) envolvendo motociclistas e pela infiltração criminosa da categoria.

6 Cada um desses métodos se subdivide, por sua vez, em procedimentos específicos: ocultação (evitação e camuflagem), dissuasão (imitação), superação (defesas físicas e defesas grupais), desestímulo (distanciamento, comunicação da intenção de fuga, despistamento e defesas simbióticas), oposição (defesas armadas, armamento repentino e defesas sociais emergentes). Ver Felson, 2006.

7 As motocicletas percorrem uma média de $33 \mathrm{~km}$ por litro de gasolina, o que chega a representar uma economia superior a $100 \%$ quando comparada aos carros brasileiros mais econômicos (Oliveira, 2003).

8 Tal competência depende de quatro características do seu ambiente de trabalho que também são compartilhadas por outros condutores profissionais: o veículo, as vias de circulação, o público (Young, 2002; Stenning, 1995) e os agentes de controle de trânsito.

\section{BIBLIOGRAFIA}

ANDERSON, E. (1990), Streetwise: race, class and changes in an urban community. Chicago, IL, University of Chicago Press.

BARBOSA, L. (1992), O jeitinho brasileiro: a arte de ser mais igual que os outros. Rio de Janeiro, Campus.

BEATO, C.; PEIXOTO, B. T. \& ANDRADE, M. V. (2004), "Crime, oportunidade e vitimização". RBCS, 19 (55): 1-18.

BEST, J. \& LUKENBILL, D. F. (1982), Organizing deviance. Nova York,Prentice Hall.

BIRCKBECK, C. (1984-1985), "El concepto de oportunidades para el delito: su definición y consecuencias". Revista Cenipec, 9: 43-81.

BRITO, C. (2008), "'Mapa da PM indica as 13 áreas mais perigosas". A Tarde, 7.set.

CANO, I. \& IOOTY, C. (2008), "Seis por meia dúzia: um estudo exploratório do fenômeno das chamadas 'milícias' no Rio de Janeiros", in Fundação Heinrich Boll, Segurança, tráfico e milícias no Rio de Janeiro, Rio de Janeiro, Fundação Heinrich Boll.

COHEN, L. \& FELSON, M. (1979), "Social changes and crime rate trends: a routine activity approach", in American Sociological Review 44:588-607.

COLEMAN, J. S. (1988), "Social capital in the creation of human capital". American Journal of Sociology, 94: 95-120.

CONKLIN, J. E. (1972), Robbery and the criminal justice system. Philadelphia/Nova York/Toronto, J. B. Lippincott Company.

CULLEY, T. H. (2002), The immortal class: bike messengers and the cult of human power. Nova York, Random House Trade Paperbacks.

DAMATTA, R. (1985), A casa e a rua: espaço, cidadania, mulher e morte no Brasil. São Paulo, Brasiliense.

EWALD, F. (2002), "The return of Descartes's malicious demon: an outline of a philosophy of precaution", in T. Baker e J. Simon (eds.), Embracing risk, Chicago, Chicago University Press, pp. 273-301.

FELSON, M. (1986), Crime and the everyday life. Thousand Oaks, Pine Forge Press. . (2006), Crime and nature. Thousand

Oaks/Londres/Nova Deli, Sage. 
FINCHAM, B. (2006), "Bicycle messengers and the road to freedom". The Sociological Review. 54 (1): 208-222.

. (2007), "Generally speaking people are in it for the cycling and the beer: bicycle couriers, subculture and enjoyment". The Sociological Review, 55 (2): 189-202.

FONSECA, A. \& BRITO, C. (2008), "Insegurança impede o acesso aos serviços públicos”. A Tarde, 7. Set.

GAMBETTA, D. \& HAMMIL, H. (2005), Streetwise: how taxi drivers establish their customers' trustworthiness. Nova York, Russel Sage Foundation.

HANNERZ, U. (1980), Exploring the city: inquiries toward an urban anthropology. Nova York, Columbia University.

HOBBS, D.; HADFIELD, P.; LISTER, S. \& WINLOW, S. (2003), Bouncers, violence and gouvernance in the night-time economy. Oxford, Oxford University Press.

HUGGINS, M. K.; HARITOS-FATOUROS, M. \& ZIMBARDO, P. G. (2006), Operários da violência: policiais torturadores e assassinos reconstroem as atrocidades brasileiras. Brasília, Editora da UnB.

IAFOLLA, V. (2004), A risky business: the governance of security in retail banks. Toronto, Centre of Criminology of the University of Toronto.

KATZ, J. (1988), Seductions of crime: moral and sensual attractions in doing evil. Nova York, Basic Books.

LINGER, D. (1992), Dangerous encounters. Stanford, Stanford University Press.

LYSAGHT, K. \& Basten, A. (2003), "Violence, fear and the 'everyday': negotiating spatial practice in the the city of Belfast", in E. Stanko, Meanings of violence. Londres, Routledge, pp. 124-242.

MACHADO DA SILVA, L. A. (2008), "Violência urbana, sociabilidade violenta e agenda pública”, in L. A. Machado da Silva (org.), Vida sob cerco: violência e cotidiano nas favelas do Rio de Janeiro, Rio de Janeiro, Nova Fronteira.

MARIN, L. \& QUEIROZ, M. S. (2000), "A atualidade dos acidentes de trânsito na era da velocidade: uma visão geral". Caderno de Saúde Pública, 16 (1), jan.-mar., São Paulo.

MATTHEWS, R. (2002), Armed robbery. Devon/ Portland, Willan Publishing.
MISSE, M. (1997), "As ligações perigosas: mercado ilegais, narcotráfico e violência no Rio". Educação e Contemporaneidade, ano 2, 1 (1): 1-26.

MONAGHAN, L. (2002), "Regulating 'unruly' bodies: work tasks, conflict and violence in Britain's night-time economy", The British Journal of Socio$\log y, 54$ (4): 403-429.

NETO, A. S.; MUTAF, J. \& AVALASCIUS, S. (s.d.), "Pelo espelho retrovisor: motoboys em trânsito". Sao Paulo, USP/NAU.

NIOSH (National Institute for Occupational Safety and Health). (1996), Violence in the workplace. Cincinnati, Department of Health and Human Services, n. 57.

OLIVEIRA, G. C. (2003), Trabalho, vitimização e criminalização no cotidiano dos motoboys. Salvador, Dissertação de mestrado, Instituto de Saúde Coletiva, UFBA.

PAES-MACHADO, E. (2006), "Espectros da violência e do crime na contemporaneidade". Caderno $C R H, 19$ (47): 165-172, maio-ago., Salvador.

PAES-MACHADO, E. \& LEVENSTEIN, C. (2004), "I'm sorry everybody, but this is Brazil: armed robbery on the buses in Brazilian cities", Brit. J. Criminol. 44: 1-14.

PAES-MACHADO, E. \& Nascimento, A. M. (2006), "Bank money shields: work-related victimisation, moral dilemmas and crisis in the bank profession". International Review of Victimology, 13: 1-25.

PAES-MACHADO, E. \& Noronha, C. V. (2002), "Policing the Brazilian poor: resistance to and acceptance of police brutality in urban popular classes (Salvador, Brazil)". International Criminal Justice Review, 12: 53-76.

RADFORD, J. (1987), "Policing male violence: police women", in J. Hanmer e M. Mayanard, Women, violence and social control, Londres, Macmillan, pp. 30-45.

RICCIO-OLIVEIRA, M. A. (2002), A vida sobre duas rodas: acidente de trabalho como acidente de trânsito no cotidiano dos motoboys. Salvador, monografia de especialização em Saúde do Trabalhador, UFBA/ISC/CESAT.

- (2005), Ases do asfalto: vitimização e responsabilização no trabalho de motoboys de Salvador. Salvador, dissertação de mestrado, Instituto de Saúde Coletiva, UFBA. 
RHODES, T. (1997), "Risk theory in epidemic times: sex, drugs and the social organization of risk behavior". Sociology of Health and Ilness, 19: 208-227.

SAMPSON, R. J.; RAUDENBUSH, S. W. \& EARLS, F. (1997), "Neighborhoods and violent crime: a multilevel study of collective efficacy". Science, 277: 918-924.

SANDERS, T. (2005), Sex work: a risky business. Devon, Willan Publishing.

SCOTT, J. (1990), Domination and the arts of resistance. Yale, Yale University Press.

SHAPLAND, J. \& HALL, M. (2005), What do we know about the effects of crime on victims? Conference on Crime, insecurity and well-being: an economic approach. Sheffield, University of Sheffield.

STENNING, P. C. (1995), Fare game, fare cop, victimization of, and policing by, taxi drivers in three Canadian cities: Report of apreliminary study. Toronto, Centre of Criminology.

ST. JEAN, P. K. B. (2007), Pockets of crime: broken window, collective efficacy and the criminal point of view. Chicago/Londres, University of Chicago Press.

TAPPARELLI, G. (1996), Os donos do pedaço: delinqüencia juvenil em um bairro da cidade de Salvador. Salvador, dissertação de mestrado em Sociologia, UFBA.

VOLKOV, V. (2002), Violent entrepreneurs: the use of force in the making of Russian capitalism. Ithaca/ Londres, Cornell University Press.

ZALUAR, A. (1994), "A moeda e a lei", in , Condomínio do diabo, Rio de Janeiro, Revan/Editora da UFRJ, pp. 219-223.

WEHR, K. (s.d.), "Bicycle messengers and fast capitalism: an old-school solution to the needs of technocapitalism”. Disponível no site <http:// www.fastcapitalism.com>.

WRIGHT, R. T. \& DECKER, S. H. (1997), Armed robbers in action. Boston, MA, Northeastem University Press.

YOUNG, G. (2002), Inside the taxi: tales from Kiwi cab drivers. Auckland, Hodder Moa Becket. 


\section{O JOGO DE ESCONDE- ESCONDE: TRABALHO PERIGOSO E AÇÃO SOCIAL DEFENSIVA ENTRE MOTOBOYS DE SALVADOR}

\section{Eduardo Paes-Machado e Maria Angélica Riccio-Oliveira}

Palavras-chave: Motoboys; Crimes predatórios; Vigilância adequada; Vantagens ecológica; Ação social defensiva.

Este artigo utiliza entrevistas semi-estruturadas e observação direta para discutir a árdua busca de segurança entre trabalhadores de moto-entrega (motoboys) de Salvador. Mostra como o déficit de vigilância faz esta categoria desenvolver uma ação social defensiva múltipla contra crimes predatórios visando seus veículos, encomendas e pertences pessoais. Demonstra como as (des)vantagens ecológicas dos espaços urbanos estruturam e são, por sua vez, estruturadas por esta ação defensiva. Estabelece ainda uma distinção entre as táticas socioespaciais restritivas, fundadas na própria capacidade de vigilância, e as táticas expansivas, envolvendo a negociação de recursos de vigilância de terceiros.

\section{PLAYING HIDE-AND-SEEK: DANGEROUS WORK AND DEFENSIVE SOCIAL ACTION AMONG MOTORCYCLE COURIERS IN SALVADOR}

\section{Eduardo Paes-Machado and Maria Angélica Riccio-Oliveira}

Keywords: Couriers; Predatory crimes; Capable guardianship; Ecological advantages; Defensive social action.

Based on semi-structured interviews and direct observation, this paper discusses the stress-filled pursuit of safety by motorcycle couriers (motoboys) in Salvador, Brazil. A lack of capable guardianship forces these workers to take multifaceted defensive social action against predatory crime to protect their vehicles, consignments, and personal belongings. The ecological (dis)advantages of urban spaces structure are, in turn, structured by this defensive action. Restrictive sociospatial tactics based on individual guardianship capabilities are compared and contrasted with expansive socio-spatial tactics involving the negotiation of guardianship resources with others. The conclusion is that, although restrictive and expansive tactics are complementary, the former are more effective means of reducing the ecological disadvantages affecting motoboys than the latter.

\section{JOUER À CACHE-CACHE: TRAVAIL DANGEREUX ET ACTION SOCIALE DÉFENSIVE ENVERS LES COURSIERS À MOTO DE SALVADOR}

\section{Eduardo Paes-Machado et Maria Angélica Riccio-Oliveira}

Mots-clés: Coursiers; Crimes prédateurs; Surveillance appropriée; Avantages écologiques; Action sociale défensive.

Cet article utilise des interviews semistructurées ainsi que l'observation directe pour aborder la pénible quête de sécurité des coursiers (à moto) de la ville de Salvador, au Brésil. Il montre de quelle façon le manque de sûreté oblige cette catégorie professionnelle à développer une action sociale défensive contre les attaques envers leurs véhicules, marchandises et biens personnels. Nous démontrons comment les (dés)avantages écologiques des espaces urbains structurent et sont à leur tour structurés par cette action défensive. Nous distinguons également les tactiques sociospatiales restrictives, fondées sur la propre capacité de vigilance et les tactiques expansives, qui englobent la négociation de ressources de vigilance de tierces personnes. 